Journal of

Pharmacy and Pharmacology

JPP 2003, 55: 000-000

(C) 2003 The Authors

Received May 21, 2003

Accepted August 19, 2003

DOI 10.1211/0022357022359

ISSN 0022-3573
Medical Mycology Unit, National Institute for Cellular Biotechnology, Department of Biology, National University of Ireland, Maynooth, Co. Kildare, Ireland

Joseph O'Keeffe, Sean Doyle, Kevin Kavanagh

Correspondence: K. Kavanagh, Medical Mycology Unit, NICB, Department of Biology, NUI Maynooth, Co. Kildare, Ireland. E-mail: kevin.kavanagh@may.ie

Funding: This work was supported by funding from the Higher Education Authority under PRTLI 3. J. O'Keeffe is the recipient of an Enterprise Ireland Post-Graduate Student

Maintenance Grant.

\section{Exposure of the yeast Candida albicans to the anti-neoplastic agent adriamycin increases the tolerance to amphotericin B}

\author{
Joseph O'Keeffe, Sean Doyle and Kevin Kavanagh
}

\begin{abstract}
Cancer patients experience a high incidence of fungal infections due to their immuno-suppressed condition. This work has investigated the interaction of an anti-neoplastic agent, adriamycin (doxorubicin), with the yeast Candida albicans and examined whether this drug altered the susceptibility of the yeast to amphotericin B-an anti-fungal agent used for the treatment of systemic fungal infections in cancer patients. Exposure to adriamycin for $24 \mathrm{~h}$ increased the growth of $C$. albicans and increased the tolerance to amphotericin B by a small, but statistically significant, extent. Growth in adriamycin-supplemented medium suppressed the respiration rate of $C$. albicans, which resulted in a decrease in the ergosterol content of the fungal cell membrane. The tolerance to amphotericin B was lost after exposure to adriamycin for $48 \mathrm{~h}$, which coincided with a restoration in the respiration rate and the ergosterol content of the fungal cell membrane. This work demonstrated that short-term exposure $(24 \mathrm{~h})$ to adriamycin increased the tolerance of $C$. albicans for amphotericin $B$, which may be mediated by a decrease in the ergosterol content as a result of an adriamycin-induced disruption of oxidative phosphorylation.
\end{abstract}

\section{Introduction}

Cancer is a debilitating, multifactorial disease that attacks indiscriminately across all demographic sectors of society. There are several families of anti-neoplastic agents used to treat cancer and these are sub-divided on the basis of their mode of action. One class of anti-neoplastic agent, the anthracyclins, are non-covalent DNA binding agents and one of these, adriamycin, was isolated in 1969 from Streptomyces peucetius (Pratt \& Ruddon 1979). Adriamycin (also known as doxorubicin) is used in the treatment of Hodgkin's disease and Non-Hodgkin's lymphoma and in cancers of the breast, ovaries and lymph system (Lowenthal \& Eaton 1996). Adriamycin is a topoisomerase II inhibitor (Cummings et al 1991) and its structure allows it to intercalate between base pairs of DNA causing subsequent template disorders, which lead to strand breakage. Adriamycin also affects mitochondrial function by selectively binding to cardiolipin in the mitochondrial membrane and disrupting the action of complex I (Parker et al 2001).

Cancer patients are at an increased risk of a range of opportunistic fungal infections by virtue of their debilitated state and the immuno-suppressive nature of anti-neoplastic regimes (Saral 1991; De Pauw 1997). The yeast Candida albicans is an important opportunistic fungal pathogen, affecting individuals whose immune systems become immunocompromised due to diseases such as leukaemia or anti-neoplastic therapy (Schuler \& Haag 1997). The incidence of infections caused by $C$. albicans has increased in recent years among immuno-compromised patients due, in part, to inefficient or incomplete therapies and by advances in medicine allowing the survival of immuno-compromised patients for prolonged periods. C. albicans accounts for between 52 and $63 \%$ of all nosocomial fungal infections, and yeast of the genus Candida are the fourth most common organisms isolated from blood (Pfaller et al 1998; Verduyn Lunel et al 1999)

Treatment of fungal infections is generally achieved by using azole or polyene antifungal agents such as amphotericin B (Schuler \& Haag 1997; Prentice et al 1999; Laverdiere et al 2000). Amphotericin B is employed to treat advanced systemic fungal infections, but its efficacy can be low (Saral 1991; Walsh et al 1999). In addition, 
amphotericin B can have severe side effects, which may limit its use in certain patient groups. However, amphotericin B still remains an important anti-fungal agent for the treatment of recalcitrant systemic fungal infections (Hartsel \& Bolard 1996). The anti-fungal activity of amphotericin B lies in its ability to bind to ergosterol in the fungal cell membrane and create pores through which cytoplasmic contents leak and protons enter, leading to cytoplasmic acidification and subsequent cell death (Abu Salah 1996).

The aim of this work was to determine whether exposure of $C$. albicans to the anti-neoplastic agent adriamycin altered the susceptibility of the yeast to amphotericin B. We postulated that in certain instances anti-neoplastic therapy may inadvertently alter the tolerance of $C$. albicans to selected anti-fungal drugs employed to arrest the development of infections in cancer patients.

\section{Materials and Methods}

\section{Growth conditions}

C. albicans ATCC 10231 was originally obtained from the American Type Culture Collection (Manasas, VA) and was grown to the stationary phase (approximately $1.5 \times 10^{8}$ cells $\mathrm{mL}^{-1}$ ) at $30^{\circ} \mathrm{C}$ overnight in yeast extractpeptone-D-glucose broth (YEPD; $1 \%(\mathrm{w} / \mathrm{v})$ yeast extract (Sigma Aldrich Chemical Co., Dorset, UK), 2\% (w/v) bacteriological peptone (Sigma Aldrich) and 2\% (w/v) glucose (Sigma Aldrich)) in an orbital incubator at 200 rev $\min ^{-1}$. Where appropriate, media were solidified by the addition of $2 \%(\mathrm{w} / \mathrm{v})$ agar (Oxoid). Yeast cultures were maintained on YEPD agar at $4{ }^{\circ} \mathrm{C}$ and sub-cultured every four to six weeks.

\section{Antifungal and anti-neoplastic agents}

Adriamycin was purchased as Doxorubicin (Ebewe Arzneimittel Gmbh., Unterach, Austria). Amphotericin B (Sigma Aldrich) was dissolved in dimethyl sulfoxide (DMSO, Sigma Aldrich) and diluted to working concentrations in sterile phosphate-buffered saline (PBS, pH 7.2) (Life Technologies, Paisley, UK) before use. The maximum DMSO concentration employed with cells was $2 \%(\mathrm{v} / \mathrm{v})$.

\section{Amphotericin B susceptibility testing}

Yeast cultures were grown to the stationary phase in antibiotic medium 3 (AB 3, Oxoid) supplemented with $2 \%(\mathrm{w} / \mathrm{v})$ glucose overnight at $30^{\circ} \mathrm{C}$ and $200 \mathrm{rev} \mathrm{min}^{-1}$. Cultures were harvested by centrifugation (2220 $\mathrm{g}$ for $5 \mathrm{~min}$ in a Beckmann GS-6 centrifuge) and diluted to $1 \times 10^{6}$ cells $\mathrm{mL}^{-1}$. Cells $\left(1 \times 10^{5}\right.$ in $\left.100 \mu \mathrm{L}\right)$ were added to each well of a 96 -well plate (Sarsdtedt, Wexford, Ireland) containing amphotericin B (Sigma Aldrich) dissolved in antibiotic medium 3 (AB3) in serial dilutions from 2.5 to $0.0048 \mu \mathrm{g} \mathrm{mL}^{-1}$. The plates were incubated at $37^{\circ} \mathrm{C}$ for $24 \mathrm{~h}$ and the optical density was read at $450 \mathrm{~nm}$ using a MRX spectrometer (Dynax Technology). The MIC90 was determined to be the lowest concentration of amphotericin B required to reduce growth by $90 \%$, relative to the control (Moran et al 1997).

Effect of pre-growth in adriamycin on the growth of C. albicans in amphotericin B AB3 medium (supplemented with $2 \%(\mathrm{w} / \mathrm{v})$ glucose and adriamycin $\left.\left(20 \mu \mathrm{g} \mathrm{mL}^{-1}\right)\right)$ was inoculated with $C$. albicans at a density of $5 \times 10^{5} \mathrm{~mL}^{-1}$ and grown at $37^{\circ} \mathrm{C}$ for $24 \mathrm{~h}$. Cells were harvested by centrifugation and resuspended in AB3 containing amphotericin $\mathrm{B}\left(0.625 \mu \mathrm{g} \mathrm{mL}^{-1}\right)$ at a density of $5 \times 10^{5}$ cells $\mathrm{mL}^{-1}$. A drug free control consisted of cells that had not been exposed to adriamycin. Cell density was determined after growth for $24 \mathrm{~h}$ using a PAMAS SVSSC Particle Counter (Rutesheim, Germany).

\section{Oxygen consumption}

Cells were grown in YEPD supplemented with adriamycin $\left(20 \mu \mathrm{g} \mathrm{mL}^{-1}\right)$ at $30^{\circ} \mathrm{C}$ for 24 or $48 \mathrm{~h}$, harvested by centrifugation and resuspended at a density of $1 \times 10^{8} \mathrm{~mL}^{-1}$ in PBS (pH 7.2). A Clark Type oxygen electrode (Rank Brothers Ltd, Cambridge, UK) was employed to determine the respiration rate of cells and the rate of oxygen consumption was expressed as the number of $\mu$ moles of oxygen consumed per minute per $1 \times 10^{8}$ cells.

\section{Sterol extraction and gas chromatography analysis}

Sterol extraction was performed as described by Arthington-Skaggs et al (1999). Equivalent wet weight samples $(2.28 \mathrm{~g})$ of stationary phase cells were resuspended in $2 \mathrm{~mL}$ denaturing solution $(20 \% \mathrm{w} / \mathrm{v}$ potassium hydroxide (Sigma Aldrich), $60 \% \mathrm{v} / \mathrm{v}$ ethanol) and placed in a $90{ }^{\circ} \mathrm{C}$ shaking water bath $\left(190 \mathrm{rev} \mathrm{min}^{-1}\right)$ for $1.5 \mathrm{~h}$. Heptane $(600 \mu \mathrm{L})$ was added to each of the samples. Samples were left in the dark until a distinct heptane layer formed. Sterols were identified using a Varian Series II Gas Chromatograph (Varian Ltd, Victoria, Australia). An ergosterol standard curve was constructed over the range $100-0.25 \mu \mathrm{g} \mathrm{mL}^{-1}$ and the lowest level of detection of ergosterol was $0.1 \mu \mathrm{g} \mathrm{mL}^{-1}$.

\section{Statistical analysis}

Using either the Kruskal-Wallis test or Mann-Whitney U test (Sigma Stat Statistical Analysis Package Version 1.00; SPSS Inc., Chicago, IL). $P$ values less than 0.05 denoted significance (Wardlaw 2000). All experiments were performed on three independent occasions and the means were expressed \pm s.e.

\section{Results}

Effect of adriamycin exposure on $C$. albicans growth and susceptibility to amphotericin B

Adriamycin did not display a significant fungistatic or fungicidal effect on $C$. albicans over the concentration range $0.1-40 \mu \mathrm{g} \mathrm{mL}^{-1}$ (data not presented). Experiments were performed to establish the response of $C$. albicans to amphoter- 


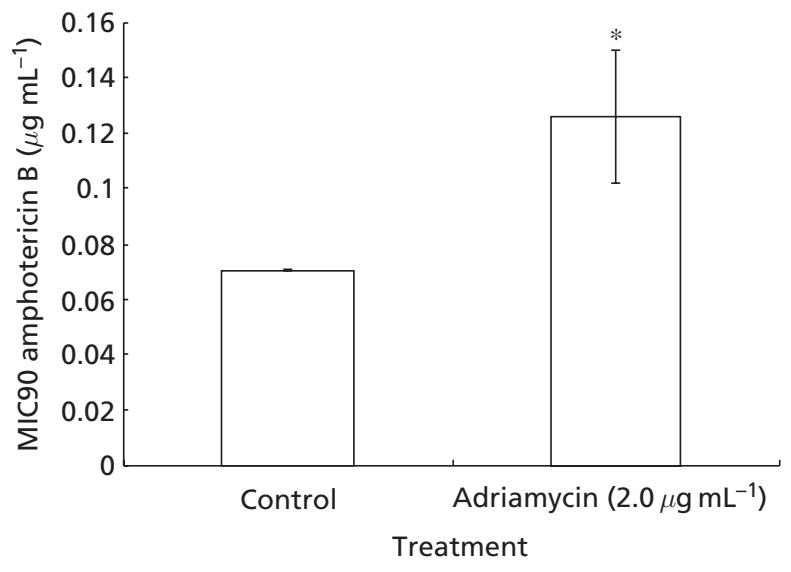

Figure 1 Amphotericin B MIC90 of C. albicans grown in AB3 supplemented with adriamycin $\mathrm{B}\left(2.0 \mu \mathrm{g} \mathrm{mL}^{-1}\right) . * P=0.05$ compared with control.

icin $\mathrm{B}$, and to amphotericin $\mathrm{B}$ when co-cultured in the presence of adriamycin $\left(2.0 \mu \mathrm{g} \mathrm{mL}^{-1}\right)$. Exposure of C. albicans in $\mathrm{AB} 3$ supplemented with adriamycin to amphotericin $\mathrm{B}$ yielded an amphotericin B MIC90 of $0.13 \mu \mathrm{g} \mathrm{mL}^{-1}$ compared with the control which gave an amphotericin $\mathrm{B}$ MIC90 value of $0.07 \mu \mathrm{g} \mathrm{mL}^{-1}$ (Figure 1). These data were significant at $P=0.05$ and indicated that 24-h exposure of $C$. albicans to adriamycin altered the susceptibility of the yeast to amphotericin B. No alteration in tolerance to the azoles, ketoconazole and miconazole, or the polyene, nystatin, was observed following pre-growth of C. albicans in adriamycin (data not presented).

Experiments were performed to determine whether a correlation existed between the enhanced tolerance of $C$. albicans to amphotericin B and cell growth. The cell density attained in the culture that had been pre-grown in adriamycin was $1.55 \times 10^{7} \mathrm{~mL}^{-1}$ whereas the cell number attained in the control was $3.57 \times 10^{6} \mathrm{~mL}^{-1}$ (Figure 2).

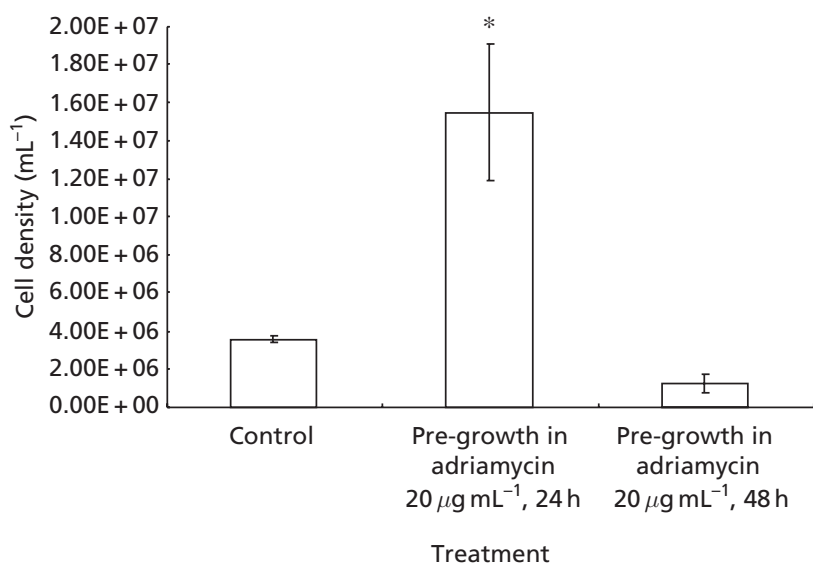

Figure 2 Growth of C. albicans in AB3 supplemented with amphotericin $\mathrm{B}\left(0.625 \mu \mathrm{g} \mathrm{mL}^{-1}\right)$ following pre-growth in adriamycin $\left(20 \mu \mathrm{g} \mathrm{mL}^{-1}\right)$ for 24 or $48 \mathrm{~h}$. ${ }^{*} P=0.05$ compared with control.
Cultures that had been exposed to adriamycin for $48 \mathrm{~h}$ showed a lower final cell density $\left(1.28 \times 10^{6} \mathrm{~mL}^{-1}\right)$ than the control.

\section{Investigation of the effect of adriamycin on respiration of $\mathrm{C}$. albicans}

The oxygen consumption of $C$. albicans pre-grown in adriamycin $\left(20 \mu \mathrm{g} \mathrm{mL}^{-1}\right)$ for 24 or $48 \mathrm{~h}$ was determined. Oxygen consumption of control cells was $9.6 \mu \mathrm{mol}$ oxygen $/ 10^{8}$ cells $\min ^{-1}$ while cells pre-grown in adriamycin for $24 \mathrm{~h}$ displayed a respiration rate of $5.4 \mu \mathrm{mol}$ oxygen $/ 10^{8}$ cells $\mathrm{min}^{-1}$, which was significantly less $(56 \%)$ than the control at $P=0.05$ (Figure 3). Cells pre-grown in adriamycin for $48 \mathrm{~h}$ demonstrated a $23 \%$ reduction in oxygen consumption ( $7.4 \mu \mathrm{mol}$ oxygen $/ 10^{8}$ cells $\mathrm{min}^{-1}$ ) relative to the control.

\section{Effect of adriamycin on the ergosterol content of C. albicans}

Ergosterol is a major component of the fungal cell membrane which helps maintain structure and regulates the influx and efflux of extra/intracellular components. Amphotericin B functions by binding to ergosterol leading to the creation of pores through which intracellular constituents leak and protons enter the cell (Abu Salah 1996). The combined effect of these two processes is the acidification of the cytoplasm and the death of the cell Resistance of fungal cells to amphotericin B is rare but, where encountered, is characterized by a reduction in the amount of ergosterol in the cell membrane (Kelly et al 1997; White et al 1998).

Ergosterol quantification by GC analysis demonstrated (Figure 4) that following growth for $24 \mathrm{~h}$ in adriamycinsupplemented medium the ergosterol content of $C$. albicans was reduced from 58.5 to $29.6 \mu \mathrm{g} \mathrm{mL}^{-1}$ (g cells) ${ }^{-1}$ (wet wt), a decrease of $49 \%$ (significant at $P=0.05$ ). Growth of

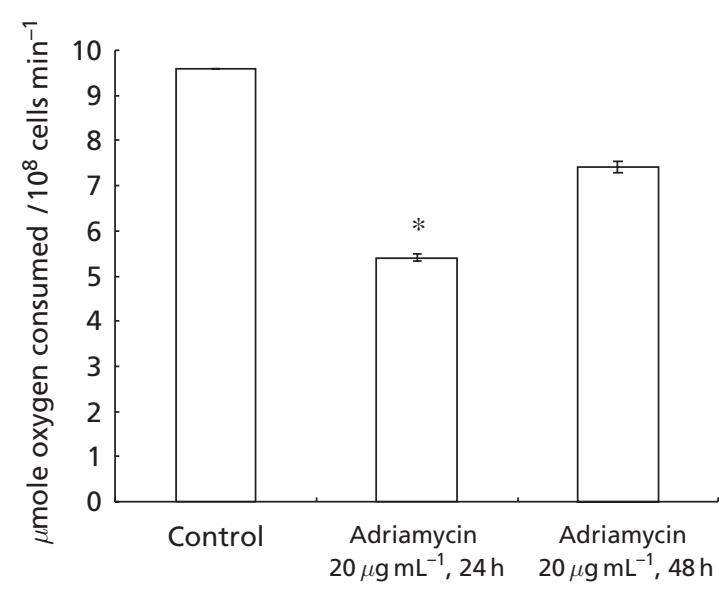

Figure 3 Oxygen consumption of $C$. albicans following growth in adriamycin $\left(20 \mu \mathrm{g} \mathrm{mL}^{-1}\right)$ for 24 or $48 \mathrm{~h} .{ }^{*} P=0.05$. 


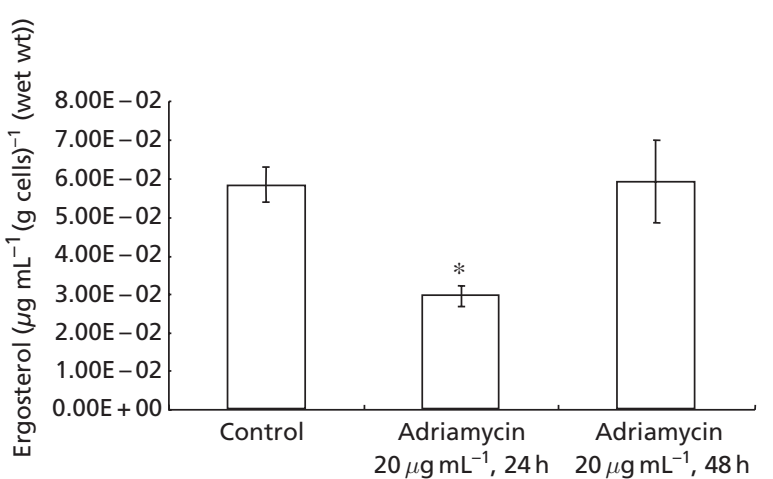

Figure 4 Ergosterol content of $C$. albicans following growth in adriamycin $\left(20 \mu \mathrm{g} \mathrm{mL}^{-1}\right)$ for 24 or $48 \mathrm{~h} .{ }^{*} P=0.05$.

C. albicans for $48 \mathrm{~h}$ in adriamycin resulted in a cellular ergosterol content similar to the control.

\section{Discussion}

The anthracycline antibiotics are one of the most widely used groups of anti-neoplastic agents for the treatment of solid and non-solid malignancies (Pratt \& Ruddon 1979; Lowenthal \& Eaton 1996). Adriamycin is an anthracycline which functions by inhibiting the action of topoisomerase II (Cummings et al 1991), inducing DNA strand breakage and kills mammalian cells by inducing apoptosis (programmed cell death) (Skladanowski \& Konopa 1993; Huschtscha et al 1995). In addition, it interacts with a phospholipid (cardiolipin) of the mitochondrial membrane leading to an alteration in the permeability of the mitochondrion with a concomitant adverse effect on oxidative phosphorylation (Parker et al 2001).

Fungal infections in cancer patients are a serious, and in some cases life-threatening, problem which arise due to the debilitated state of the patient or as a consequence of immuno-suppression induced by anti-neoplastic therapy (De Pauw 1997). Amphotericn B is one of the anti-fungal agents used for the treatment of systemic fungal infections frequently seen in leukaemic and solid tumour patients (Hartsel \& Bolard 1996) and acts by binding to ergosterol in the fungal cell membrane and creating pores through which intracellular constituents escape (Abu Salah 1996).

This study demonstrated that exposure of C. albicans to the anti-neoplastic agent adriamycin, led to an increase in tolerance to amphotericin B (Figure 1). Pre-exposure to adriamycin resulted in higher cell growth in the presence of amphotericin B (Figure 2). While adriamycin did not affect the viability of $C$. albicans to a significant extent it did reduce oxygen consumption (Figure 3). Cells exposed to adriamycin for $24 \mathrm{~h}$ showed a $56 \%$ reduction in respiration and demonstrated a reduced amount of ergosterol (Figure 4). Ergosterol biosynthesis requires a functional mitochondrion for the provision of NADPH which is necessary for one of the intermediate stages in its biosynthesis (Daum et al 1998). The depleted ergosterol con- tent of adriamycin-treated cells might have been a consequence of their depressed respiration rate. In contrast, the ergosterol content of cells grown in the presence of adriamycin for $48 \mathrm{~h}$ was similar to the control, which reflected the higher respiration rate in these cells relative to that in cells exposed to adriamycin for $24 \mathrm{~h}$.

Exposure of C. albicans to adriamycin for $24 \mathrm{~h}$ caused a small, but statistically significant, increase in tolerance to amphotericin $\mathrm{B}$, which might have been due to the depleted ergosterol levels as a result of the reduced respiration rate. Adriamycin affects respiration by binding to the phospholipid cardiolipin (diphosphatidylglycerol) - a component of the mitochondrial membrane (Cummings et al 1991; Parker et al 2001). This has the effect of disrupting membrane permeability and inhibiting the action of complex I (Prebble 1981; Das \& Mazumdar 2000), which is a critical component of the electron transport chain of oxidative phosphorylation in C. albicans (Helmerhorst et al 2002). It is postulated that adriamycin binds to cardiolipin which disrupts the action of complex I leading to a depression in the respiration rate. This leads to depleted levels of NADPH (which is required for ergosterol biosynthesis), reduced levels of ergosterol and an increase in tolerance of amphotericin B. While tolerance of amphotericin B is clinically rare (Van den Bossche et al 1998) it has been observed in cases where ergosterol levels are depleted leaving fewer binding sites for amphotericin B (Kelly et al 1997; White et al 1998; Kontoyiannis \& Lewis 2002). Reduced levels of ergosterol have been implicated in fluconazole tolerance in C. albicans (Loffler et al 2002). In this case it was postulated that ergosterol deficient mutants had an altered membrane permeability that retarded the entry of fluconazole.

The reappearance of susceptibility to amphotericin B after growth of C. albicans in adriamycin for $48 \mathrm{~h}$ was accompanied by a simultaneous restoration in the respiration rate and ergosterol content of the cell. The resumption of respiration might have been due to the cells replacing cardiolipin damaged by adriamycin in the initial $24 \mathrm{~h}$. As a consequence, respiration resumed at near normal levels with a concomitant increase in the ergosterol level leading to a restoration in the susceptibility to amphotericin B.

This work demonstrated that adriamycin anti-neoplastic therapy had the potential to increase the tolerance of C. albicans for amphotericin B by disrupting respiration, which had an adverse effect on the ergosterol content of the fungal cell membrane. This may have deleterious consequences for cancer patients and could lead to the appearance of amphotericin B-tolerant $C$. albicans infections in patients receiving adriamycin anti-neoplastic therapy.

\section{Conclusion}

Short-term exposure $(24 \mathrm{~h})$ to adriamycin increased the tolerance of C. albicans for amphotericin B, which may be mediated by a decrease in the ergosterol content as a result of an adriamycin-induced disruption of oxidative phosphorylation. 


\section{References}

Abu-Salah, K. M. (1996) Amphotericin B: an update. Br. J. Biomed. Sci. 53: 122-133

Arthington-Skaggs, B. A., Warnock, D. W., Morrison, C. J. (1999) Quantitation of ergosterol content: novel methods for determination of fluconazole susceptibility of Candida albicans. J. Clin. Microbiol. 37: 3332-3337

Cummings, J., Anderson, L., Willmott, N., Smyth, J. F. (1991) The molecular pharmacology of doxorubicin in vivo. Eur. J. Cancer 27: 532-535

Das, T. K., Mazumdar, S. (2000) Effect of adriamycin on the boundary lipid structure of cytochrome $c$ oxidase: pico-second time-resolved fluorescence depolarization studies. Biophys. Chem. 86: 15-28

Daum, G., Lees, N. D., Bard, M., Dickson, R. (1998) Biochemistry, cell biology and molecular biology of lipids of Saccharomyces cerevisiae. Yeast 14: 1471-1510

De Pauw, B. E. (1997) Practical modalities for prevention of fungal infections in cancer patients. Eur. J. Clin. Microbiol. Infect. Dis. 16: 32-41

Hartsel, S., Bolard, J. (1996) Amphotericin B: new life for an old drug. J. Pharmacol. Sci. 17: 445-449

Helmerhorst, E. J., Murphy, M. P., Troxler, R. F., Oppenheim, F. G. (2002) Characterisation of the mitochondrial respiratory pathways in Candida albicans. Biochim. Biophys. Acta Bioenergetics 1156: $73-80$

Huschtscha, L. I., Bartier, W. A., Malstrom, A., Tatersall, M. H. (1995) Cell death by apoptosis following anticancer drug treatment in vitro. Int. J. Oncol. 6: 585-593

Kelly, S. I., Lamb, D. C., Kelly, D. E., Manning, N. J., Loeffler, J., Herbart, H., Schumacher, U., Einsele, H. (1997) Resistance to fluconazole and cross resistance to amphotericin B in Candida albicans from AIDS patients caused by defective sterol $\Delta^{5,6}$ desaturation. FEBS Lett. 400: 80-82

Kontoyiannis, D. P., Lewis, R. E. (2002) Antifungal drug resistance of pathogenic fungi. Lancet 359: 1135-1143

Laverdiere, M., Rotstein, C., Bow, E. J., Roberts, R. S. (2000) Impact of fluconazole prophylaxis on fungal colonisation and infection rates in neutropenic patients. J. Antimicrob. Chemother. 46: 1001-1008

Loffler, J., Einsele, H., Hebart, H., Schumacher, U., Hrastnik, C., Daum, G. (2000) Phospholipid and sterol analysis of plasma membranes of azole resistant Candida albicans strains. FEMS Microbiol. Lett. 185: 59-63

Lowenthal, R. M., Eaton, K. (1996) Toxicity of Chemotherapy. Hematology/Oncology Clinics North America 10: 967-990
Moran, G., Sullivan, D. J., Henman, M. C., McCreary, C. E., Harrington, B. J., Shanley, D. B., Coleman, D. C. (1997) Antifungal drug susceptibilities of oral Candida dubliniensis isolates from human immuno-deficiency virus (HIV)-infected and nonHIV infected subjects and generation of stable fluconazole resistant derivatives in vitro. Antimicrob. Agents. Chemother. 41: $617-623$

Parker, M. A., King, V., Howard, K. P. (2001) Nuclear magnetic resonance study of doxorubicin binding to cardiolipin containing magnetically orientated phospholipid bilayers. Biochim. Biophys. Acta Biomembranes 1514: 206-216

Pfaller, M. A., Jones, R. N., Messer, S. A., Edmond, M. B., Wenzel, R. P. (1998) National surveillance of nosocomial blood stream infection due to Candida albicans: frequency of occurrence and anti-fungal susceptibility in the SCOPE programme. Diagnostic Microbiol. Infect. Dis. 31: 327-332

Pratt, W. B., Ruddon, R. W. (1979) The Antibiotics. In: The Anticancer Drugs. Chapter 7, Oxford University Press, New York

Prebble, J. N. (1981) Resolution of the respiratory chain and oxidative phosphorylation In: Mitochondria, Chloroplasts and Bacterial Membranes. Chapter 9, Longman Group Ltd., New York

Prentice, H. G., Caillot, D., Dupont, B., Menichetti, F., Schuler, U. (1999) Oral and intravenous itraconazole for systemic fungal infections in neutropenic haematological patients. Acta Haematol. 101: 56-62

Saral, R. (1991) Candida and Aspergillus infections in immunocompromised patients: an overview. Rev. Infect. Dis. 13: 487-492

Schuler, U. S., Haag, C. (1997) Prophylaxis of fungal infections. Mycoses 40: 41-44

Skladanowski, A., Konopa, J. (1993) Adriamycin and daunomycin induce programmed cell death (apoptosis) in tumour cells. Biochem. Pharmacol. 46: 375-382

Van den Bossche, H., Dromer, F., Improvissi, I., Lozane-Chiu, M., Rex, J. H., Sanglard, D. (1998) Anti-fungal drug resistance in pathogenic fungi. Medical Mycology 36: 119-128

Verduyn Lunel, F. M., Meis, F. G., Voss, A. (1999) Nosocomial fungal infections: Candidemia. Diagn. Microbiol. Infect. Dis. 34: $213-220$

Walsh, T. J., Finberg, R. W., Arndt, C., Hiemenz, J. (1999) Liposomal amphotericin B for empirical therapy in patients with persistent fever and neutropenia. N. Engl. J. Med. 340: 764-771

Wardlaw, A. L. (2000) Practical Statistics for Experimental Biologists. Wiley \& Sons Inc., Chichester, UK

White, T. C., Marr, K. A., Bowden, R. A. (1998) Clinical, cellular and molecular factors that contribute to anti-fungal drug resistance. Clin. Microbiol. Rev. 11: 382-402 